Proceedings of the 2011 Winter Simulation Conference

S. Jain, R.R. Creasey, J. Himmelspach, K.P. White, and M. Fu, eds.

\title{
ASSESSING INTER-ORGANIZATIONAL DYNAMICS OF MANUFACTURING SERVICE SUPPLY CONTRACTS
}

\author{
Zbigniew J. Pasek \\ University of Windsor \\ 401 Sunset Ave. \\ Windsor, ON, CANADA N9B 3P4
}

\begin{abstract}
The practice of service-based manufacturing, utilized in various industries, particularly in electronics, pharmaceuticals, and automotive, is on the rise as it improves enterprise effectiveness in dynamic markets. The mutual responsibilities between the supplier(s) and user(s) of such services are spelled out in defined-time-horizon contracts. While such contracts define mutual obligations of both parties involved on a tactical/operational level, their long-term strategic objectives may be in conflict. This paper is focused on studying the dynamics of the manufacturing service contracts. It investigates the factors affecting the shape of the negotiation space for such contracts, and also the way it should be navigated in response to changing market conditions. The paper presents analytical framework developed to facilitate behavior analysis of the actors involved in the contract.
\end{abstract}

\section{INTRODUCTION}

Among the new paradigms developed to deal with highly competitive and fast-paced global markets, leasing manufacturing related services and capacity is recognized as a promising solution, as it requires no investment in capacity and maintenance, and involves no ownership of physical assets for the lessee. This practice is recommended by many experts and has been successfully employed by various well-known companies including Novartis Pharmaceuticals Corporation (Borchardt 2000), Microsoft, Ericsson, Handspring and HP (O'Brien 2001), to name a few. In IT industries alone, it is estimated that about half of manufacturing activities is outsourced, accounting for more than $\$ 500$ billion worth of products (O'Brien 2001). Similar trend is predicted for the automotive industry (MMC and FG 2004).

\section{BACKGROUND}

Service-based manufacturing is an extension of traditional outsourcing. Outsourcing emerged as a key operational strategy in the 1990s. Today outsourcing of IT/IS related activities is a standard practice for many companies (Osei-Bryson and Ngwenyama 2005) and is also extensively analyzed in literature.

In a service-based manufacturing scenario, the manufacturer-supplier relationship does not follow traditional buyer-supplier pattern as the buyer "asks for competencies rather than either only parts or only manufacturing capacity" (Urbani, Molinari-Tosatti, and Pasek 2002). Two different actors can often be distinguished. One is the End User (EU), who interacts with the market of finished goods as a direct market supplier; its core business is the interaction itself. The EU often adds its value to the product through innovation, design, marketing and branding. Another actor is the Manufacturing Service Provider (MSP), who takes on responsibility for the manufacturing response to market and for customization. Its core business, then, is manufacturing itself, which drives its focus on the necessary competencies and, consequently, leads to increased effectiveness in that area. 
The mutual responsibilities between actors are defined by a contract signed for a defined time horizon. While such a contract must meet the requirements of both parties involved, each party may be viewing it from a strategically different point of view: the EU evaluates the attractiveness of choosing a service-based supply of manufacturing capacity (based on cost, quality, responsiveness, etc.), while an MSP's decision is based on its own effectiveness and, thus, on the profit margin gained on the job. Both actors also have to take into account other associated risks and uncertainties, e.g., the uncertainties in demand, technology, market changes, and the risks of investment. Although the contract can be subject to future modifications reflecting the need to respond to market unpredictability, they may yield additional costs, such as penalties and renegotiation expenses, which need to be considered as well.

Akbarzadeh and Pasek (2008) developed an analytical framework for analyzing the behaviors of the actors towards a manufacturing service supply contract. They classified the possible contractual relationship cases into 6 categories based on the attributes of the service under contract and power structure. They analyzed the negotiation space and equilibrium point in each case and concluded that the more balanced the power of the parties and the more standard the service contracted, the better the efficiency of a service-based supply approach for the whole industry in long term. Such a framework can be of great help to executives before and after bidding or signing off manufacturing services supply contracts. Contract or risk managers can use the developed model to have a clear understanding of their position in negotiations, relative to their business partners, and can categorize the service they are committing to deliver. Such understanding will help them make better choices about the type and terms of the contract, and be more proactive while negotiating the contract. In summary, this framework can support managers' decisionmaking by establishing standardized and formal contract management processes and improve the effectiveness of Contract Lifecycle Management (CLM).

\section{CONTRACT SCENARIOS STUDIED}

Considering the balance of power and the attributes of the manufacturing service under contract, six possible scenarios can be considered Akbarzadeh and Pasek(.)(2008Figure 1 shows the sources of different types of power (Neves 2000) whose weighted sum determines parties' relative power.

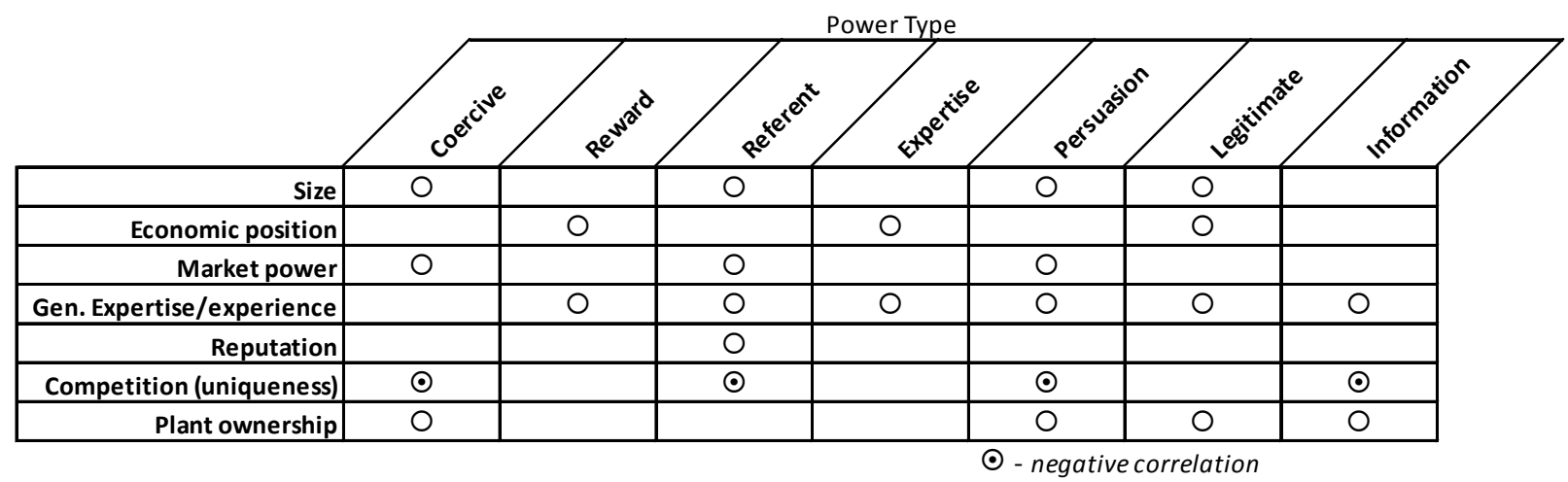

Figure 1. Different types of power and their sources

The six possible combinations of two key factors, i.e., service attributes (commodity vs. specific service) and the balance of power, can be considered as six scenarios as illustrated in Figure 2.

Mathematical analysis performed in Akbarzadeh and Pasek (2008) shows the amount of hypothetical risk involved in each scenario. According to that, the riskiest scenarios are Scenario C, Scenario A, and Scenario F. The least risky scenarios, on the other hand, are Scenario E, Scenario B, and Scenario D (Figure 3). Thus, the focus in this paper is on the riskiest scenarios and application of the given framework to them to assess the probability of failure for each, followed by comparison of results. 


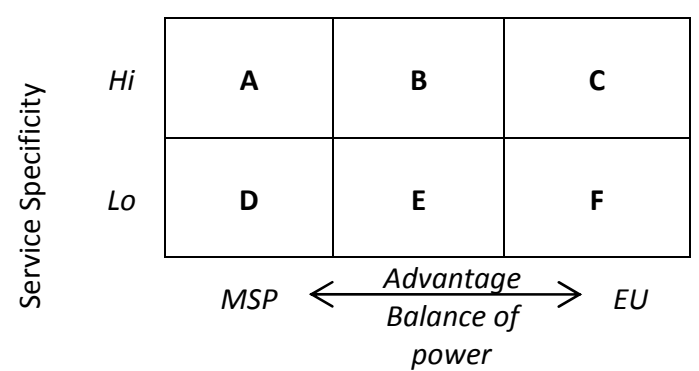

Figure 2: Possible contract scenarios

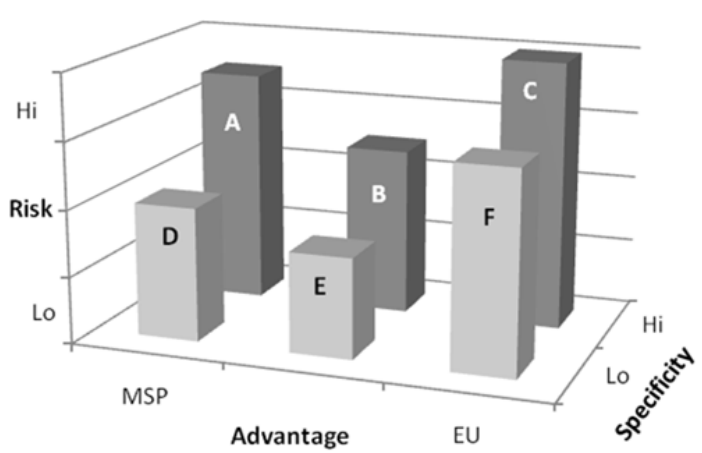

Figure 3: Hypothetical riskiness of various contract scenarios

\section{COST BREAKDOWN STRUCTURE}

To calculate the costs the MSP incurs, the cost structure described in Akbarzadeh and Pasek (2008) is used. The MSP rents its service to the EU for a defined period of time, $\bar{t}$, and a leasing price, $L$. MSP's net present value (NPV) can be formulated as:

$$
N P V_{M S P}= \begin{cases}\int_{0}^{t}\left(L-C_{M S P}\right) \cdot e^{\rho . t} d t & \text { if } \bar{C}_{M S P}<L \\ \int_{0}^{t}\left|\left(L-C_{M S P}\right)\right| \cdot\left(e^{-\rho . t}-2\right) d t & \text { otherwise }\end{cases}
$$

where $\bar{C}_{M S P}$ is MSP's total costs of delivering the service, $\rho$ is the opportunity cost of money for the MSP, $B=\left(1-e^{-\rho}\right) / \rho$, and $\bar{t}$ is the time horizon of the contract. To normalize, the MSP's cost items as their percentage of $L$ are considered with $L=100$, and $\bar{t}=1$. Thus, the percentage of net present value is:

$$
N P V_{M S P}= \begin{cases}B\left(100-\bar{C}_{M S P}^{\prime}\right) & \text { if } \bar{C}_{M S P}<L \\ (B-2)\left(\bar{C}_{M S P}^{\prime}-100\right) & \text { otherwise }\end{cases}
$$

Using this formula the losses will be magnified in the same way the profits are reduced as a result of lost opportunities and considering opportunity costs.

Considering the implications of Transactions Costs Economy (TCE), $\bar{C}_{M S P}$ can be broken down as:

- Production costs $\left(C_{\text {prod }}\right)$

- Investment (machinery, human resources, processes, peripheral)

- Operational costs

- Adjustment costs for changes in volume or product specifications (Walker and Weber 1987)

- Transaction costs $\left(\mathrm{C}_{\mathrm{T}}\right)$

- Ex ante (deterministic/fixed): bidding, negotiation, legal, and contracting costs, and other charges that might be incurred to set up the relationship (Osei-Bryson and Ngwenyama 2006).

- Ex post (stochastic): reporting, communication, transition (Osei-Bryson and Ngwenyama 2006), renegotiation, conflict resolution, penalties, law suits, publicity, marketing, and adaptation costs.

- Opportunity costs $(\rho)$ (Akbarzadeh and Pasek 2008). 
We assume that the ex ante transaction costs, $C_{e x-a n t e}$, have been already incurred and are inputs to the model, and that opportunity costs, $\rho$, are also given and remain constant during the contract's time horizon. These three main categories of costs are going to be considered in the model and the costs resulting from the actualization of risk factors are added to appropriate cost categories in a linear manner.

\section{PROBABILITY OF FAILURE}

The purpose of the model is to study the probability of failure of the contract. Thus, one first needs to define success or failure. Here, failure is defined as the occurrence of one or more of the following fatal risk factors, defined in terms of binary variables:

- $\quad$ Financial loss $(F L o)$

$$
F L o= \begin{cases}1 & \text { if } S G_{M S P}<\varepsilon \\ 0 & \text { otherwise }\end{cases}
$$

- Incomplete contract (IC)

$$
I C= \begin{cases}1 & \text { if } P_{I C} \geq \hat{P}_{I C} \\ 0 & \text { otherwise }\end{cases}
$$

- Loss of partner $(L o P)$

$$
L o P= \begin{cases}1 & \text { if } P_{\text {LoP }} \geq \hat{P}_{L o P} \\ 0 & \text { otherwise }\end{cases}
$$

- Loss of image/reputation $(L o I)$

$$
L o I= \begin{cases}1 & \text { if } P_{L o I} \geq \hat{P}_{L o I} \\ 0 & \text { otherwise }\end{cases}
$$

Probability failure of a contract can be defined as the weighted sum of the above random variables:

$$
P_{\text {Failure }}=F L o^{*} W_{F L o}+I C * W_{I C}+L o P^{*} W_{L o P}+L o I^{*} W_{L o I}
$$

where, $W_{F L o}+W_{I C}+W_{L o P}+W_{L o I}=1$, and, therefore, $0<P_{\text {Failure }}<1$.

Note that considering the linear cost accumulation formula and the definition of Financial Loss and Failure, we convert the continuous total costs, and therefore NPV, to discrete step-wise probabilities of financial loss and failure. In other words, first, costs are accumulated and the NPV is calculated using equation (2). Then, if the NPV obtained is smaller than a pre-defined threshold (pre-set positive value, assuring, for example, no less than $3 \%$ return), FLo will be equal to 1 , which will, in turn, lead to an increase in $P_{\text {Failure }}$ by $W_{F L o}$.

\section{RISK ASSESSMENT PROCESS}

The generic risk assessment process utilized in Houston, Mackulak, and Collofello (2001) is going to be used as a roadmap. This process is composed of the following stages:

1. Identifying the risk factors. This stage involves analyzing the power structure and the attributes of the service under contract to identify the most important risk factors which can potentially lead to the failure of the contract. 


\section{Pasek}

2. Modeling the system to incorporate the risk factors. In this stage, the inter-relationships between the risk factors are described and modeled.

3. Quantifying risk factor uncertainties. Here, random variables are defined to quantify the uncertainties associated with each risk factor. Afterwards, a distribution function is assigned to each defined random variables using various methods, such as, for example, fitting distributions to historical data or using the opinions of experts.

4. Propagating the uncertainties. At this stage the model is exercised to output the probability of failure.

5. Sensitivity analysis. Having the probability of failure resulting from previous stages, the model can be used to find alternatives which help decrease the probability of failure.

To model the contractual relationship of the MSP and the EU, who is leasing the manufacturing services for a defined time horizon, a hierarchy of risk factors is developed using a mixture of bottom-up and top-down methods. Figure 4 illustrates the way risk factors are organized in a three-level hierarchy. The hierarchy illustrated in this figure is the output of the risk identification process and is used as the input of risk quantification and modeling process.

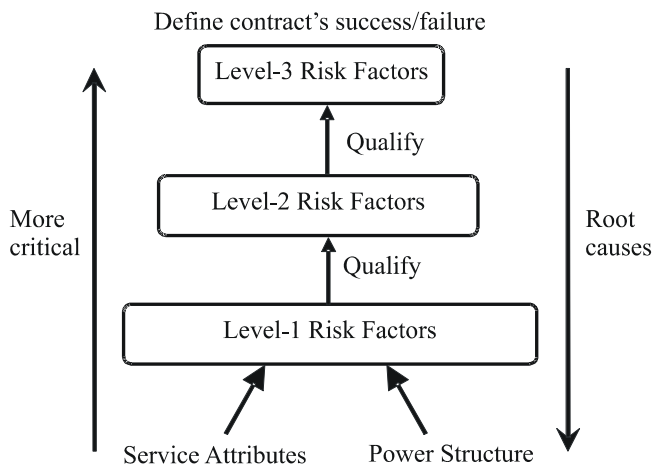

Figure 4: Risk Factors Structure

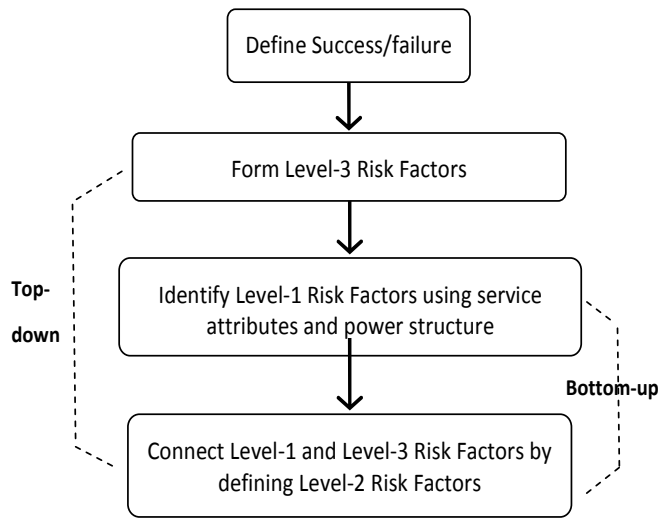

Figure 5: Modeling Risk Factors Process

Such hierarchy, in which each level qualifies the next level, if it passes a defined threshold, makes devising risk mitigation, and management plans easier and more efficient since it considers the root cause of each risk factor. Moreover, each Level-2 and Level-3 risk factor can be traced back to one or more Level-1 risk factor. Thus, if the root cause Level-1 risk factors of each higher level risk factor are controllable, the higher level risk factor can be also managed and controlled through managing and controlling its root cause.

\section{IDENTIFYING RISK FACTORS}

In this stage the three-level hierarchy of risk factors is constructed using a mixed method, i.e., a combination of top-down and bottom-up methods as shown in Figure 5. This means that, first, starting from the top, Level-3 risk factors are identified, then, from the bottom, the first level of the structure is built, and, finally, by connecting these two levels, the second level of the structure is constructed. The steps followed in this stage are as follows:

Step 1: Identifying and Modeling Level-3 risk factors

1. Considering the objective function and the definition of failure, provided in the previous section, list Level-3 risk factors. From the definition these fatal risk factors are as follows:

- Financial loss

- Loss of image/reputation

- Loss of partner 
- Incomplete contract

2. Find the cause-and-effect relationships between the identified risk factors.

Step 2: Identifying and Modeling Level-1 risk factors

1. List the attributes of the service under contract and the direction of the power.

2. Consider the attributes listed in sub-step 1, brainstorm their possible implications and effects, and list the most important relevant risk factors, in terms of both the probability of occurrence and the severity of the potential outcomes, resulting from each attribute. These risk factors form the first level of risk factors of the model.

3. Find the cause-and-effect relationships between the identified risk factors.

4. List the impacts of each Level-1 risk factor.

Step 3: Identifying and Modeling Level-2 risk factors

1. Consider Level-1 and Level-3 risk factors and find out how the Level-3 risk factors can be resulting from the Level-1 ones, considering the impacts of Level-1 risk factors found in step 2. List the most important risk factors resulting from the actualization of Level-1 risk factors which can potentially lead to Level-3 risk factors, considering their potential impacts. These risk factors form the Level-2 risk factors of the model.

2. Find the cause-and-effect relationships between the identified risk factors.

To identify the risk factors, their impacts, and their interrelationships, risk factor lists mentioned in the literature, brainstorming sessions, Delphi method, or experts' opinions can be used as guidelines, depending on their availability.

\section{QUANTIFYING RISK FACTOR UNCERTAINTIES}

To quantify the risk factors, various methods including analysis of historical data, brainstorming, surveys, and questionnaires can be used. Also, some risk factors already modeled in the literature (especially in Boehm 1991; Houston, Mackulak, and Collofello 2001) can be reused. To model correlated variables, since different variables follow different distributions, the so called "distribution-free" approach or Spearman's rank order correlation coefficients should be used. General process is as follows:

1. Start from the Level-1 risk factors and move in a bottom-up manner to higher levels. Define quantified measures for each risk factor in terms of random variables using their impacts, similar to what is done for the fatal risk factors in defining the objective function. Note that one risk factor can be translated into more than one random variable.

2. Consider the cause-and-effects relationships between the risk factors and translate these relationships into qualification relationships between the random variables defined in the previous substep. Also, consider that co-movements of variables in the same direction and in the opposite direction, i.e., situations when a high value of one variable means a high or low value for another variable, and quantify these co-movements by setting up a correlation matrix.

3. Assign a probability distribution function to each random variable associated with each risk factor, along with the correlations between each two correlated random variables.

4. For each qualification relationship, define a threshold, whose violation activates the dependent risk factor(s), using either brainstorming or available data.

\section{MULTI-STAGE MONTE-CARLO METHOD}

Monte Carlo Simulation is useful method for risk assessment and management because it helps in studying the behavior of the system given the uncertainties of risk factors. It allows for studying the outcomes (success or failure) of the system in the event of various possible values of random variables associated with risk factors. Thus, a Monte Carlo Simulation method was used to propagate the uncertainties of risk factors identified, modeled and quantified in the previous steps of the proposed methodology. 
Using the multi-stage Monte Carlo simulation technique, the model was stochastically simulated using the random variables of the first level of risk factors as the inputs, and the Level-3 risk factors, and the failure probability, as the outputs of the simulations model. Figure 6 summarizes the simulation process.

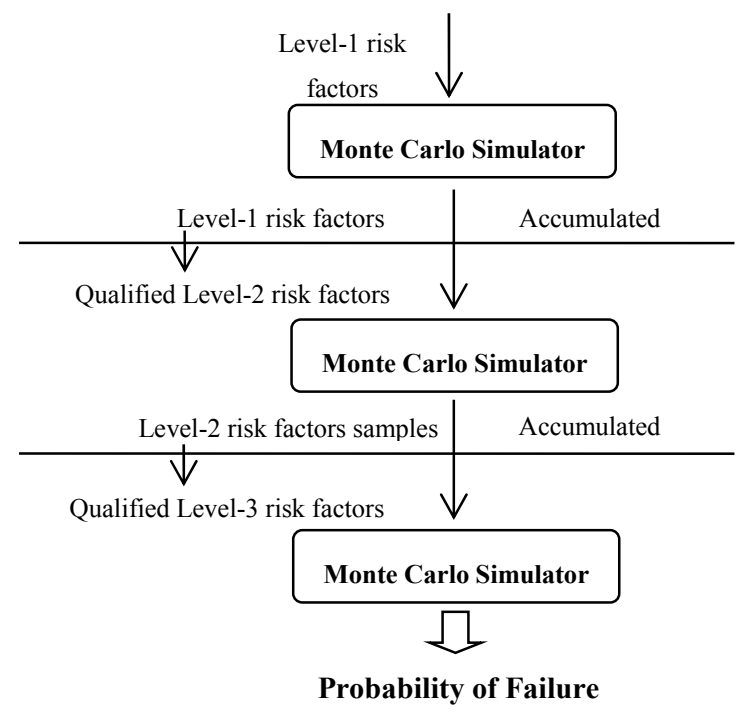

Figure 6: Multi-stage Monte Carlo approach used

The required number of simulations was determined using the jack-knife technique (Haimes 1998). Jack-knife technique works as follows: start with an arbitrary number of simulations, N, and run the simulation twice to get two answers. Compare the answers; and if the difference between the two results is more than a predefined limit, ê, double the simulations to $2 * \mathrm{~N}$. Keep doubling the number of simulations until the error is smaller than ê.

It should be pointed out that using Monte Carlo Simulation implies that the proposed framework model falls in the category of classical risk management models.

To implement the simulation model, a Microsoft Excel add-on called @Risk was is used for performing risk analysis using Monte Carlo simulation (Palisade Corporation 2004).

\section{SENSITIVITY ANALYSIS}

The objective of this stage is to identify the most significant root causes of failure, evaluate their impacts, and check if they can be controlled, and if yes, assess the impact of controlling them on the probability of failure. This means that in this stage, the main attempt is to find the Level-1 risk factors which contribute the most to failure of the contractual relationship.

To do this, a regression sensitivity analysis using tornado graphs is carried out. To perform regression sensitivity analysis, a multiple linear regression based on the simulation run results is done using the selected outputs (e.g., probability of failure) as the dependent variable and the values of random variables, defined to quantify risk factors, as the independent variables. The standardized regression coefficients of independent variables are then graphed in a decreasing order on a tornado diagram (Myerson 2005).

The beta coefficient of an independent variable shows the number of standard deviations by which the independent variable increases by one standard deviation, having fixed all other independent variables. The bigger the absolute value of a beta coefficient, the most influential the associated random variable.

The $R^{2}$ value can be used as a measurement of the percentage of variation explained by the linear relationship. If $R^{2}<\sim 0.6$, the relationship between the inputs and outputs cannot be assumed to be linear.

Hence, using the generated tornado graph, it is possible to visually identify the most significant random variable in terms of their impact on the selected output. Since each random variable is associated 


\section{Pasek}

with a certain risk factor, this means that the most influential risk factors can be also identified. Furthermore, from previous stages, it is known which Level-1 risk factor(s) are the root cause(s) of each Level-2 and 3 risk factors. Thus, tornado graphs resulting from regression sensitivity analysis can be used to help identifying the main root causes of failure (as the main output of the simulation model) and evaluating their severity.

\section{CASE STUDY: SCENARIO C}

As mentioned before, Scenario $\mathrm{C}$ is the riskiest scenario as it involves supplying a specific service for an EU which is in superior position power wise. Start-up companies providing innovative services will most likely fall into this category.

In scenario $\mathrm{C}$, according to the definition of specificity, the service under contract is a complex and novel service which involves a high degree of asset specificity, for both physical and human resources related assets. Also, as a result of the market conditions or the nature of the service, it has to be delivered to the EU, and to the market, in a short time, or otherwise its value will depreciate significantly over time.

Note that as in this scenario the balance of power is in favor of the EU, all managerial categories of uncertainties (e.g., time, information, and control), have to be considered. This means that the risk factors associated with this scenario have higher likelihood and severity and are less controllable.

\subsection{Identifying Risk Factors}

The risk factors associated with this scenario were identified and modeled using the methodology described in section 7.

Step 1: Level-3 risk factors (already discussed in Section 7)

Step 2: Level-1 risk factors

The risk factors directly resulting from the attributes of the contracted manufacturing service, which form the main part of the first level of the hierarchy, are represented in Figure 7 (the risk factors are boxed), showing the cause-and-effect relationships between these risk factors. Moreover, as the balance of power is in favor of the EU, it will probably behave opportunistically to maximize its own profit. Thus, "EU's Opportunistic Behavior" is the most important risk factor resulting from EU's superior power. The impacts of Level-1 risk factors are summarized in Table 1. Studying the potential impacts of Level-1 risk factors helps with identifying Level-2 risk factors.

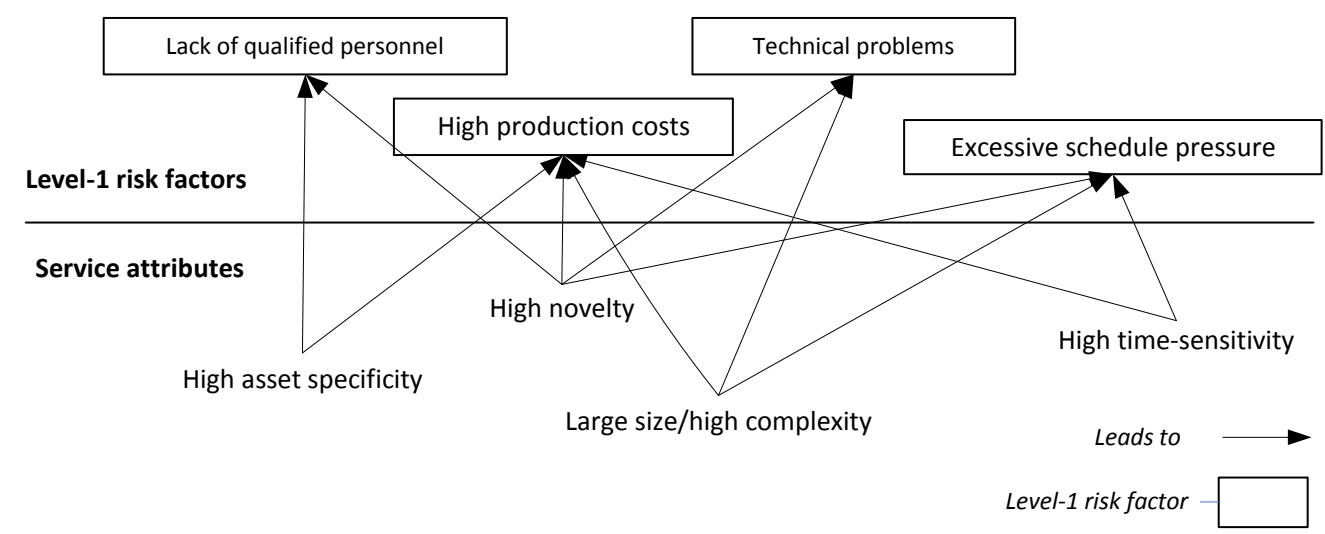

Figure 7: Level-1 risk factors rooted in nature of contracted service in Scenario C

\section{Step 3: Level-2 risk factors}

The first level of risk factors, if actualized, give rise to the second level of risk factors, which are more fatal and can directly cause the MSP to fail. For simplicity, this step is illustrated in Figure 8 (Level2 risk factors are in bold boxes). 
Table 1: The impacts of Level-1 risk factors

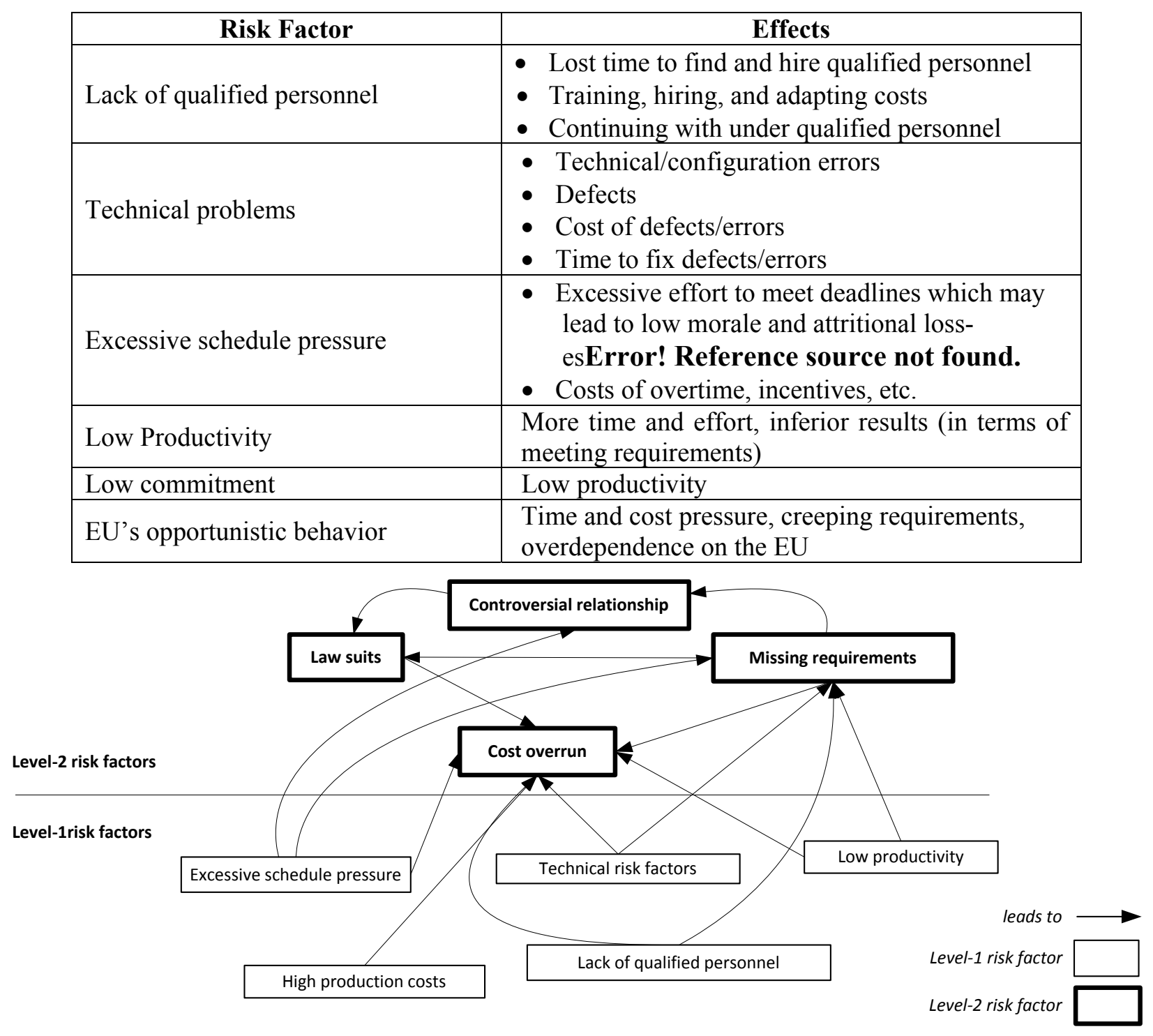

Figure 8: Level-2 risk factors rooted in service attributes in Scenario C

To quantify the risk factors, various methods including analysis of historical data, brainstorming, surveys, etc. can be used. Also, some risk factors already well modeled in the literature (especially in Houston, Mackulak, and Collofello 2001) can be used. To model correlated variables, since each variable may follow different distributions, the "distribution-free" approach or Spearman's rank order correlation coefficients should be used (Corder and Foreman 2009).

\subsection{Propagating the Uncertainties}

Figure 9 shows the schematic presentation of the simulation model, while Figure 10 shows the cost breakdown structure of each cost category, without considering opportunity costs. All the cost items under Total $C_{p r o d}$ and Total $C_{\text {ex-ante }}$ are in addition to the original $C_{p r o d}$ and $C_{\text {ex-ante }}$. Total costs $\left(\bar{C}_{S M P}\right)$ are subtracted from $\left(100-L^{-}\right)$and are applied to equation (2) to calculate the Net Present Value (NPV) of delivering the manufacturing service for the MSP. 


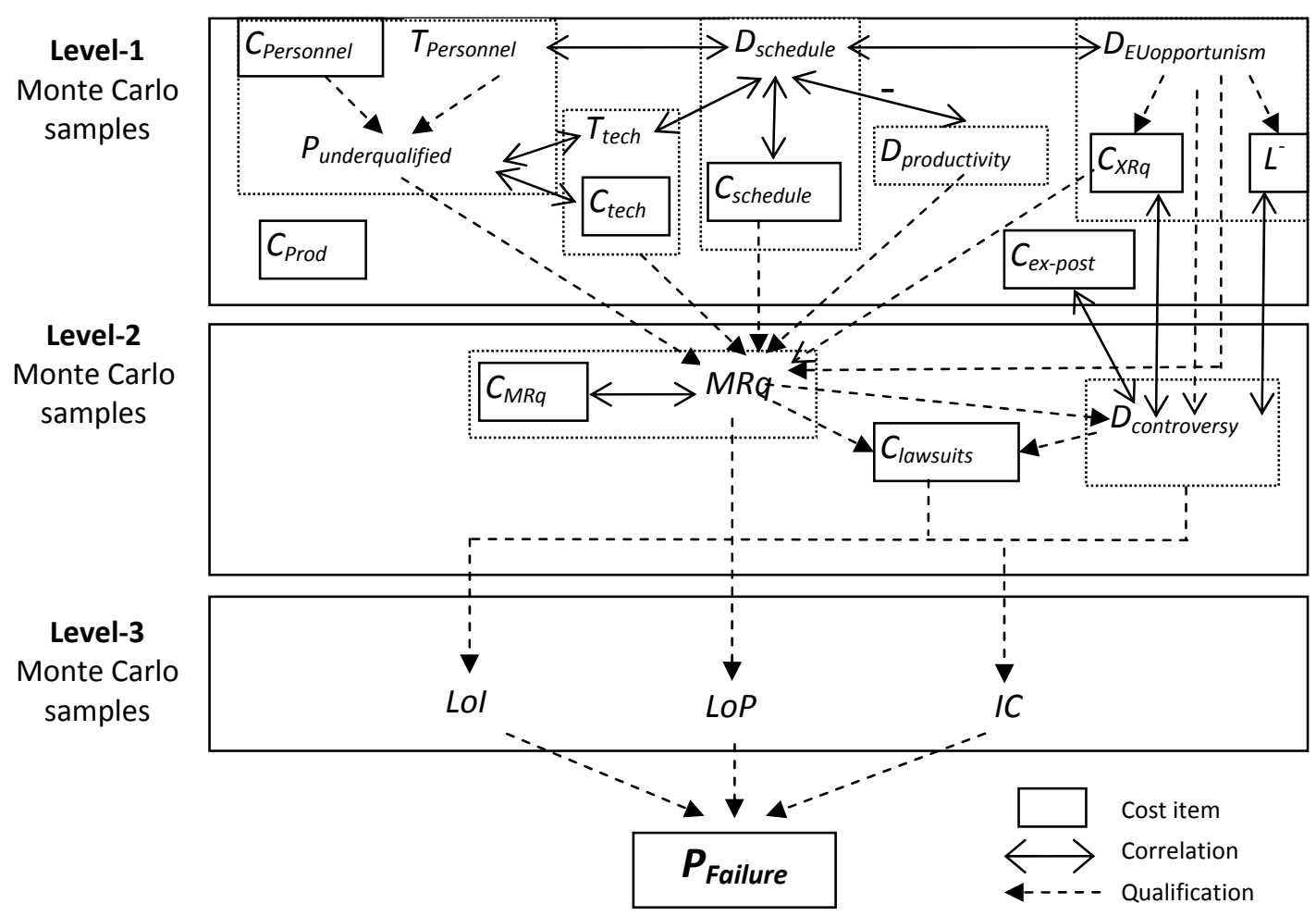

Figure 9. Schematic view of the simulation model

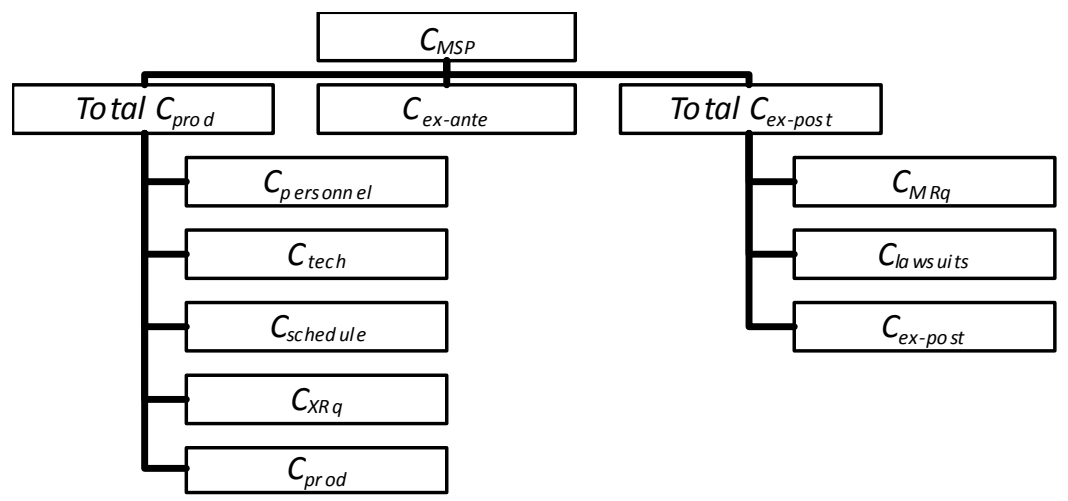

Figure 10: Cost breakdown structure

Considering $W_{F L o}=0.15 ; W_{I C}=0.25 ; W_{L o P}=0.4 ; W_{L o I}=0.2, \rho=\$ 0.5$ (Boehm 1991), $\hat{e}=0.005$, and that production costs $\left(C_{\text {prod }}\right)$ follows $\mathrm{N}(50,20)$ distribution, the following results were obtained after running 40,000 simulations.

Note that when the MSP (as in scenario C) offers a novel complex service to a more powerful and reputable EU, the weight of Financial Loss is considered less than the weight of Loss of Partner and Loss of Image. This is consistent with what is seen in real world when start-up companies even accept some monetary loss to build relationship with promising customers and to establish a good reputation in the market. 


\section{INTERPRETATION OF RESULTS}

Table 3 summarizes the results obtained from simulating the numerical examples of the three scenarios. The simulation results are consistent with the hypothesis mentioned in Akbarzadeh and Pasek (2008), and the probability of failure in Scenario C is the most, followed closely by Scenario A, and lastly Scenario F. The probability of failure in Scenario $\mathrm{C}$ is very high at 32 percent. Moreover, the probability of financial loss is also very high and, on average, there is a $60 \%$ chance that the contract results in negative NPV, especially because the EU might be able to impose price cuts of up to $30 \%$ of the original price.

Table 3: Summary results for three scenarios

\begin{tabular}{|c|c|c|c|}
\hline & C & A & F \\
\hline Probability of failure & $32 \%$ & $30 \%$ & $24 \%$ \\
\hline Key failure root cause & EU opportunism & MSP opportunism & EU's opportunism \\
\hline Key risk factor & $\begin{array}{c}\text { Controversial } \\
\text { relationship }\end{array}$ & MSP opportunism & $\begin{array}{c}\text { Controversial } \\
\text { relationship }\end{array}$ \\
\hline
\end{tabular}

According to the regression sensitivity analysis performed to identify the most influential risk factors on Financial Loss (Figure 11) EU's opportunistic behavior, which is a Level-1 risk factor and is the root cause of several other risk factors, is the most dangerous risk factor, followed by high production costs, represented by $C_{p r o d}$, and costs of missing and creeping requirements, $C_{M R q}$ and $C_{X R q}$, respectively.
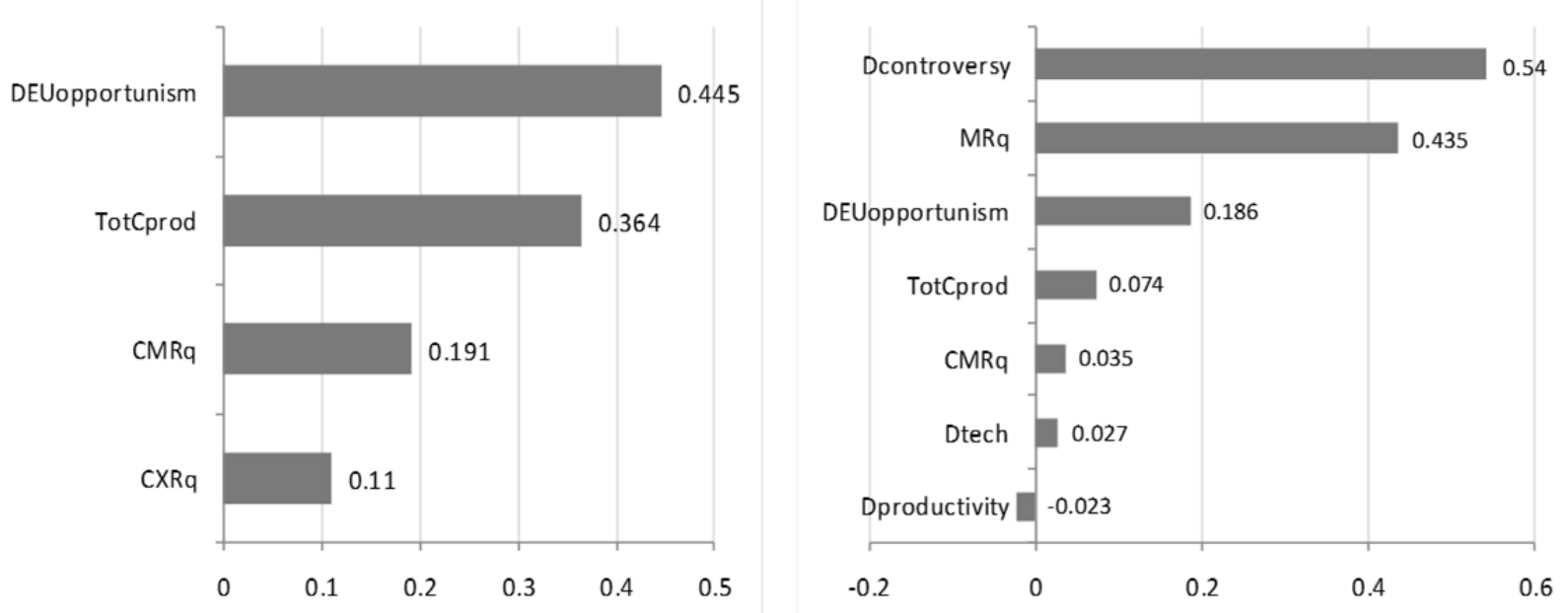

Figure 11: Regression sensitivity analysis for (a) financial loss, and (b) probability of failure

On the other hand, since on average $33 \%$ of the original and creeping requirements of the EU, mostly in terms of time and budget, are not met, and the degree of controversy is most probably "high", the mean of $D_{\text {controversy }}=3$, on the defined 1-4 scale, the chances of losing the EU and not being able to establish a good reputation, referring to the success of such contract, are also relatively high.

From Figure 11 and the fact that controversial relationship is partially a result of missing requirements, it can be concluded that "Missing Requirements" is the most influential risk factor that can cause the contract to fail. However, since "Missing Requirements" is a Level-2 risk factor, "EU's opportunistic behavior" and "High production costs" are the main root causes of failure. As the only controllable Level1 risk factor whose controlling can potentially save the contract is "high production costs," not only Scenario $\mathrm{C}$ is the riskiest scenario but also its corresponding risk factors are mostly uncontrollable. 


\section{SUMMARY}

Interestingly, in all the three scenarios, even in scenarios $\mathrm{C}$ and $\mathrm{A}$, where the manufacturing service contracted is a highly specific one, the most influential risk factor is not high production costs but it is the opportunistic behavior of the more powerful party. The potential long-term and short-term threats of controversial relationships resulting from one party's opportunistic behavior, shirking, and pressuring are widely known and many research efforts are focused on finding ways to manage and control these risk factors. This is also consistent with current industry trends in sourcing arrangements which is moving towards partnerships and joint ventures to offset the effects of lack of balance and help both partners benefit equally from the contract.

\section{REFERENCES}

Akbarzadeh, N., and Z. J. Pasek. 2008. "An Analytical Model for Manufacturing Service Supply Contract.” Journal of Manufacturing Systems 27:70-76.

Boehm, B.W. 1991. "Software Risk Management: Principles and Practices." IEEE Software 8(1):32-41.

Borchardt, J. K. 2000. "Playing the Economic Game with Outsourcing." Modern Drug Discovery 3(3): 28-34.

Corder, G.W., and D. I. Foreman. 2009. Nonparametric Statistics for Non-Statisticians: A Step-by-Step Approach. Hoboken, NJ: John Wiley \& Sons, Inc..

Haimes, Y. Y. 2009. Risk Modeling, Assessment, and Management. Hoboken, NJ: John Wiley \& Sons, Inc.

Houston, D.X., G. T. Mackulak, and J. S. Collofello. 2001."Stochastic Simulation of Risk Factor Potential Effects for Software Development Risk Management." Journal of Systems and Software 59(3):247-257.

MMC and FG (Mercer Management Consulting and Fraunhofer Gesellschaft). 2004. Future Automotive Industry Structure (FAST) 2015.

Myerson, R. B. 2005. Probability Models for Economic Decisions. Boston, MA: Cengage Learning.

Neves, M. F. 2000. "Contract Analysis as a Marketing Educational Tool.” Accessed March 30, 2011. http://www.favaneves.org/arquivos/acn005.pdf.

Palisade Corporation2004. Guide to Using@Riskv.4.5.

O'Brien, J. B. 2001. "The Making of the Xbox". Wired Magazine, Vol. 9. http://www.wired.com/wired/archive/9.11/flex.html.

Osei-Bryson, K., and O. K. Ngwenyama. 2006. "Managing Risks in Information Systems Outsourcing: An Approach to Analyzing Outsourcing Risks and Structuring Incentive Contracts." European Journal of Operational Research 174: 245-264.

Urbani, A., L. Molinari-Tosatti, and Z. J. Pasek. 2002."Manufacturing Practices in Dynamic Markets: Reconfigurability to Enable a Service-Based Manufacturing Capacity Supply." In Proceedings of the ASME International Mechanical Engineering Congress and Exposition, IMECE2002-32876. New Orleans, LA: American Society of Mechanical Engineers.

Walker, G., and D. Weber. 1987. "Supplier Competition, Uncertainty, and Make-Or-Buy Decisions." Academy of Management Journal 30(3): 589-598.

\section{AUTHOR BIOGRAPHY}

ZBIGNIEW J. PASEK is an Associate Professor at the Department of Industrial and Manufacturing Systems Engineering at the University of Windsor. He holds a $\mathrm{PhD}$ in Mechanical Engineering from the University of Michigan. His research interests include manufacturing systems automation, risk management, health care engineering and informal engineering education. He is a member of IEEE, ASME, SME, and ASEE. His e-mail address is zjpasek@uwindsor.ca. 